\title{
MONITORING OF RETAINING STRUCTURES ON AN OPEN EXCAVATION SITE WITH 3D LASER SCANNING
}

\author{
H.J. Seo*, Y. Zhao, J. Wang \\ Civil Engineering Department, Xi'an Jiaotong-Liverpool University, Suzhou, China \\ * Corresponding author
}

\begin{abstract}
Three-dimensional (3D) laser scanning techniques evolved significantly in terms of accuracy and resolution in recent years and now demonstrate a great potential for structural displacement monitoring. Laser scanners can capture the 3D profile of a structure and can be used for displacement monitoring of all visible surfaces. While the traditional techniques (total station, inclinometer, and theodolite measurements) measure displacements sparsely at several sampled points on the structure. In this work, a 3D laser scanner was used to monitor displacement of a ring beam and a reinforced soil mixing wall (SMW) at an open excavation site. Seven scans of the SMW were taken during the excavation. 3D point clouds of the SMW produced with these scans are placed in one consistent coordinates system and the difference between each pairs of consecutive scans were analysed to determine displacements of the SMW. Several cloud comparison methods were applied including $\mathrm{C} 2 \mathrm{C}, \mathrm{C} 2 \mathrm{M}$ and $\mathrm{M} 3 \mathrm{C} 2$ techniques to identify displacements along the height of the SMW. The displacement obtained were validated against displacement measured by inclinometer and total station. It is concluded that the displacement monitoring with $3 \mathrm{D}$ laser scanner are sufficient for monitoring of cumulative displacement but not for increment displacement.
\end{abstract}

\section{Introduction}

Retaining structures are generally constructed before excavation to prevent the movement of ground. Failure of retaining wall and is likely to lead to catastrophic results, economically and socially. The collapse of the retaining wall occurs most frequently during construction. Thus, it is essential to monitor and/or predict the displacement of retaining structures during the construction. Traditional displacement measurement techniques such as total station, inclinometer, and tiltmetre can take a reading at discrete key points where the sensors or targets are installed (Mohamad et al., 2012). Although various sensors are installed in places where the structure is likely to be destroyed, large displacements can occur where sensors or targets are not installed. Three dimensional (3D) laser scanning techniques developed significantly in terms of accuracy and resolution in recent years and demonstrate a great potential for structural health monitoring. Because laser scanner can capture the 3D profile of the surface of a structure across its dimension and the $3 \mathrm{D}$ profile can be analysed for the purpose of displacement monitoring.

Terrestrial laser scanning, also called LIDAR (light detection and ranging), was originally an advancement in geodetic survey techniques but has gained its popularity in a variety of applications including quantification of sediment transportation (Bremer and Sass, 2012, O'Neal and Pizzuto, 2011, Lague et al., 2013), assessment of slope stability(Nguyen et al., 2011), survey of forest vegetation (Crespo-Peremarch et al., 2018), and even the moisture content of building exterior(Suchocki and Katzer, 2018). In summary, terrestrial laser scanning is non-destructive, efficient for large area, and provides high spatial resolution. Its applications in structural health monitoring (Pesci et al., 2011, Riveiro et al., 2016, Acikgoz et al., 2017, Xu et al., 2018, Vorobyev et al., 2018) are limited and mostly recent, mainly because of three aspects of limitation, which are: (a) it requires specialised operational skill and relatively high expense (purchase or rental of a laser scanner) to acquire the $3 \mathrm{D}$ point clouds (b) it requires numerical technique and large computational power to process the $3 \mathrm{D}$ point cloud (c) the accuracy of measurement is generally inferior to that of traditional structural monitoring method. In this research, the authors aim to explore to what extent the 3D laser scanning method can supplement or even replace traditional structural monitoring method by application on a real site.

\section{Data acquisition onsite}

In this research, terrestrial laser scanning were conducted to monitor the displacement of retaining structures on a construction site in Suzhou Industrial Park where a factory warehouse was under construction. The warehouse consists 3 storeys, one basement storey and two storeys above the ground. To excavate to the foundation and basement storey of the warehouse, retaining structures were constructed. The main retaining structure were cantilever soil mixing wall (Figure 1(a)) and ring beam atop (Figure 1(b)). During the excavation, these retaining structures are scanned to produce $3 \mathrm{D}$ point clouds. 3D point clouds of the retaining structures produced by laser scans were placed in one consistent coordinates system and then the difference between each pairs of consecutive scans were analysed to determine displacements of the retaining structures. It is a legislative requirement that the displacement of retaining structures are 
monitored and reported routinely during according to (China, 2009). The alerting threshold specified for ring beam and Soil Mixing Wall (SMW) are shown in Table 1. It was uncertain whether structure monitoring by laser scanning, as an innovative application, could be sufficiently accurate and robust. Thus, inclinometer and total station measurements were also taken in order to comply with the legal requirements. The displacement obtained using 3D laser scanning were compared with and supplemented by displacement measurement by inclinometer and total station. The potential of applying terrestrial laser scanning technique to structural displacement monitoring were explored on this basis.

Table 1 alarming threshold for structural monitoring in Chinese legislation.

\begin{tabular}{lll}
\hline Alarming threshold & SMW & Ring beam \\
\hline $\begin{array}{l}\text { Daily } \\
\text { displacement }(\mathrm{mm})\end{array}$ & 4 & 3 \\
$\begin{array}{l}\text { Cumulative } \\
\text { displacement }(\mathrm{mm})\end{array}$ & 50 & 25 \\
\hline
\end{tabular}

Figure 1 (a) indicates the SMW and (b) indicates the ring beam

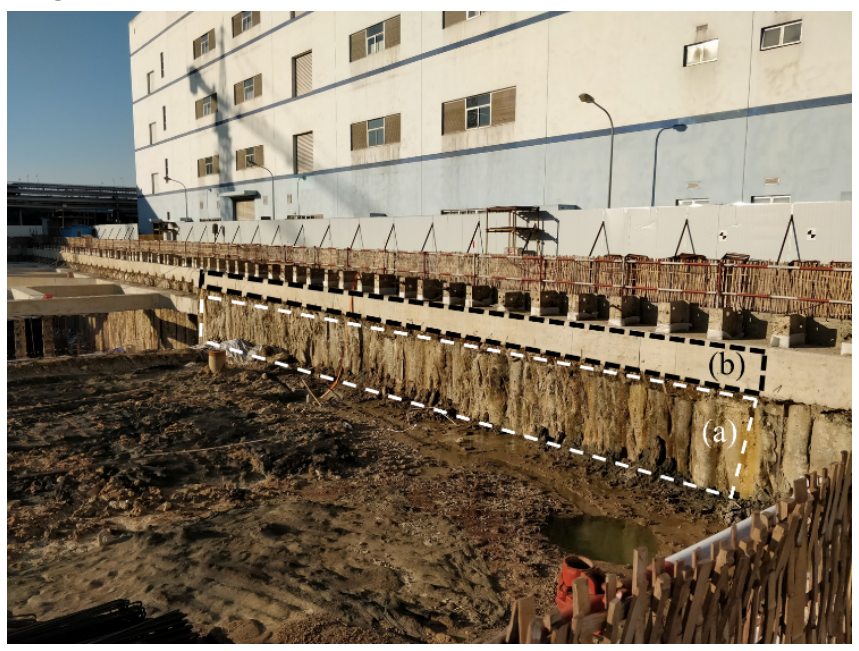

A Leica P40 laser scanner was used onsite. The Leica P40 laser scanner works on a time of flight principle. Principally, the scanner emit a pulse laser towards the object and received the reflected pulse laser. Then the distance between the object surface and scanner can be calculated as the product of time of flight multiplies the speed of light. Based the measurement, the 3D point cloud of the subject can be obtained.

Before the scanning, printed black and white target were stickered on the temporary perimeter wall of the site as shown in Figure 2. The perimeter wall are approximately parallel to the SMW, which offers an unblocked view to the perspective to the scanner. The laser scanner was installed and levelled on a tripod standing on an immediate side of the excavation as shown in Figure 2. The position of scanner is selected so that it is as close as possible to the soil mixing wall and also ensures the entire length of the soil mixing wall is in the field of view of the scanner. Before the global scan, each reference target was manually aimed at and scanned locally at higher resolution. The resolution for the global scan was set as $2 \mathrm{~nm}$ at $20 \mathrm{~m}$. The range accuracy guaranteed by the manufacture is $1.2 \mathrm{~mm}$ adding on $10 \mathrm{ppm}$ of measurement range (Geosystems, 2017). In our scans, the objects, namely the SMW and the ring beam are safely within the range of 40 meter from the scanner. Thus, the distance measurement error of a single point is within $1.6 \mathrm{~mm}$. Moreover, due to the high spatial resolution, the measurement error can be reduced by averaging the position of hundreds of neighbouring point during analysis.

The location of inclinometer and total station measurement is also shown in Figure 2. The inclinometer is installed in the ground behind the SMW as it is assumed that the displacement of SMW and neighbouring ground is equivalent in (China, 2009).

Figure 2 Setup of data acquisition onsite

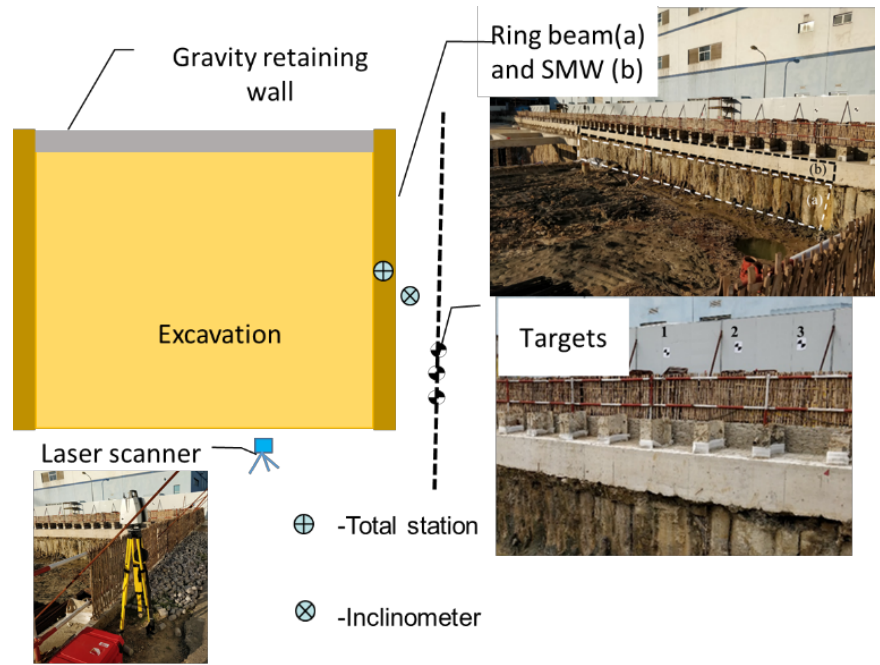

\section{Data registration}

Seven scans were successfully conducted from 29th June 2018 to 19 th July 2018. For the convenience of discussion, they are numbered in chronic order as shown in Table 2

Table 2 Numbering of scans

\begin{tabular}{ll} 
Heading & Heading \\
\hline 1 & 29 th June \\
2 & 3 rd July \\
3 & 4 th July \\
4 & 6 th July \\
5 & 12th July \\
6 & 13th July \\
7 & 19th July
\end{tabular}


For each scan, an arbitrary Cartesian coordinate system was formulated following three rules: (a) the position of scanner is the origin. (b) The initial orientation of the scanner is in the positive direction of $\mathrm{x}$-axis. (c) The gravity is in the negative direction of z-axis

In Figure 3, Scan 1 and Scan 2 are put together in their respective default coordinate system. It is obvious that the SMW and ring beam are in quite different orientation and position. Because the default coordinate systems are not necessarily consistent among all scans. Thus, to compare the distance of point clouds produced by several scans. All point clouds need to be aligned in one consistent coordinate system. By matching the position of corresponding targets 1, 2 and 3, all 8 scans are aligned as shown in Figure 4 . Such process is termed registration and was conducted with the aid of Cyclone(Geosystems, 2015). The alignment is fine by visual inspection on the point clouds. However, small amount of registration error exists. Registration error is the mismatched distance between corresponding targets, which are optimised using Least squares method. The mean registration error is $0.001 \mathrm{~m}$ and the maximum is $0.004 \mathrm{~m}$. The registration error for each pair of targets were shown in table 3 . The amount of registration error is smaller than those reported by previous researchers (Petley et al., 2005, Milan et al., 2007, Olsen et al., 2009, Abellán et al., 2009, Schürch et al., 2011). The registration was further adjusted by matching the exterior of a building near the excavation site using iterative closest point method.

Figure 3 Two scans before alignment

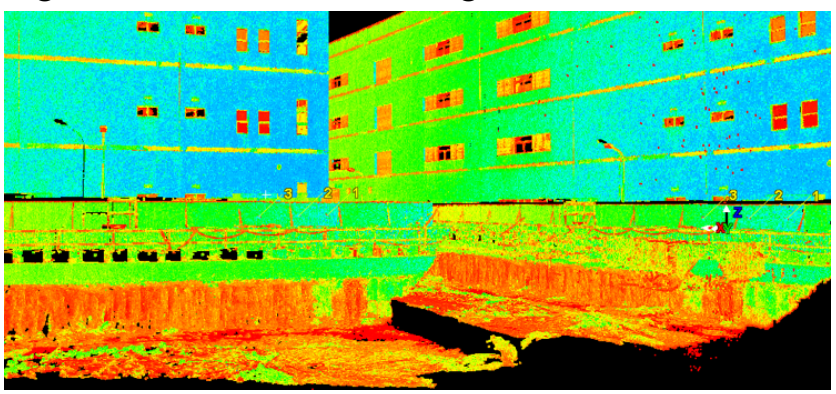

Figure 4 All scans after alignment (registration)

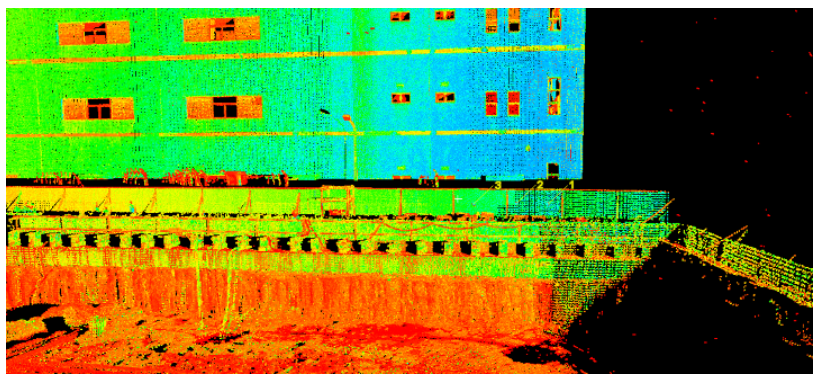

\section{Principles and comparison of methods for estimation of distance between point clouds}

\subsection{Overview}

There are mainly two types of point clouds distance estimation method used by previous researchers. One is the Piecewise Alignment Method (Acikgoz et al., 2017), where an element of the cloud is viewed as an entire rigid body and another is distance comparison based individual points and local meshing (Lague et al., 2013). For the PAM method, it was realised in MATLAB. In the latter type, there are 3 different approaches namely, Cloud to Cloud (C2C), Cloud to Mesh (C2M), Multiscale Model to Model Cloud Comparison (M3C2). All of these 3 approaches were realised in (software, 2018). The principles of each method to estimate the distance between point clouds are described herein.

\subsection{Piecewise Alignment Method (PAM)}

To utilise the PAM, the point clouds of structure on different dates are segmented into corresponding pieces. Within a pair of corresponding elements (piece), the reference cloud is translated and rotated to match with compared cloud using Iteratively Closest Point (ICP) algorithm. The displacement between the compared cloud and reference cloud is calculated as the vector pointing from the original reference cloud to the reference cloud after transformation (represented by triangles in Figure 5 ). The displacement of an individual key point or mean displacement of a group of points can be used to represent the displacement of the point cloud. An iterative procedure is applied to match the displacement of connecting edge points of neighbouring elements.

Figure 5 Illustration of PAM

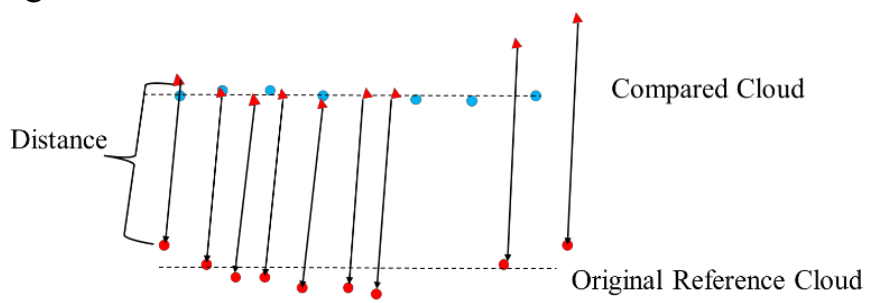

\subsection{Cloud to Cloud (C2C)}

As shown in Figure 6, one of the paired point clouds was defined as compared point cloud and another as reference point cloud. Principally, for any point in the compared cloud, the $\mathrm{C} 2 \mathrm{C}$ algorithm find its closest point in the reference cloud. Then the distance of such pair of points are computed. After repeating such distance calculation for each point in the compared cloud. The distance between these two clouds is determined as the mean value of computed distance of each point in compared cloud. 
Figure 6 Illustration of $\mathrm{C} 2 \mathrm{C}$ approach

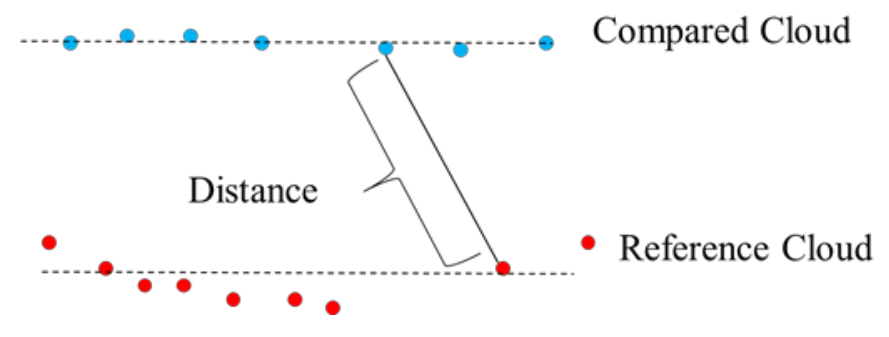

\section{2. Cloud to mesh (C2M)}

Firstly, a mesh is generated for the reference cloud with the least-square best fitting plane principle as indicated by the solid line in Figure 7. Then, for each point in the compared cloud, the distance to the generated mesh is calculated. The distance between these two clouds is determined as the mean value of computed distance of each point in compared cloud.

Figure 7 Illustration of $\mathrm{C} 2 \mathrm{M}$ approach

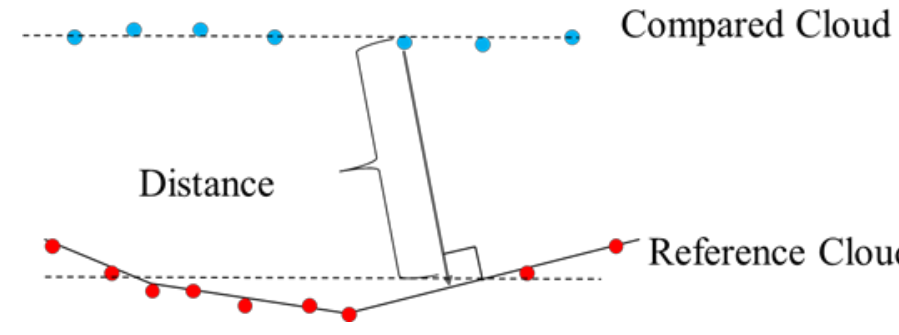

\subsection{Multiscale Model to Model Cloud Comparison (M3C2)}

The process of $\mathrm{M} 3 \mathrm{C} 2$ approach is illustrated in Figure 8 with numbered tags. Firstly, the a set core points are subsampled from the compared cloud according to a user-defined core point resolution, which is the minimum distance between two core points. Secondly, for any given core point $i$, the surface normal for each core point is estimated by fitting a plane to all points in the original compared cloud within $\mathrm{D}_{\mathrm{n}} / 2$ distance of core point I. Thirdly, a cylinder of radius $D_{d} / 2$ is defined in a way that the axis of the cylinder is in the estimated normal direction and goes through core point $i$. The height of the cylinder can be infinite or a user-defined value. All points in the compared cloud encompassed by the cylinder are projected to the axis and the mean position of projections is obtained. Similarly, all points in the reference cloud encompassed by the cylinder are projected to the axis and the mean position of projections is obtained. Finally, the distance between the pair of mean positions of projections are computed. The distance between these two clouds is determined as the mean value of computed distance of each core point in compared cloud.
Figure 8 Illustration of $\mathrm{M} 3 \mathrm{C} 2$ approach

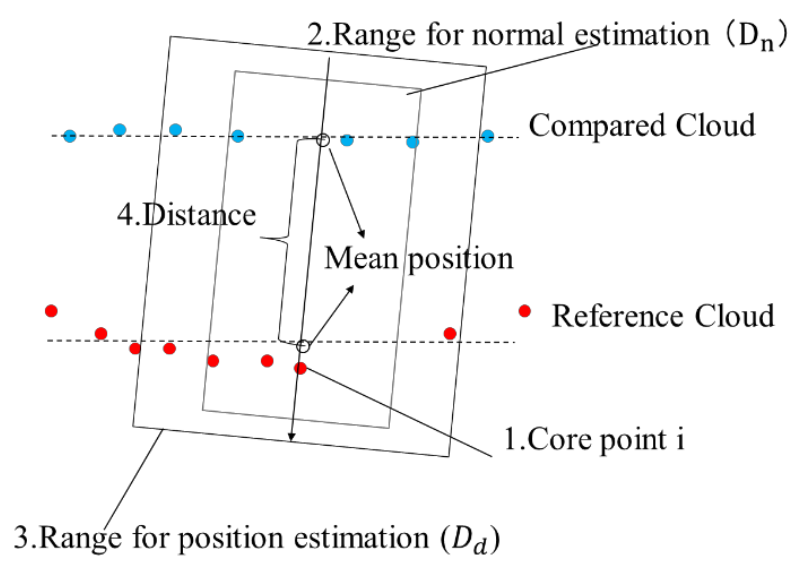

\subsection{Evaluation of performance of $C 2 C, C 2 M$ and $M 3 C 2$ on ring beam and $S M W$}

As discussed in previous paragraph, the principles of $\mathrm{C} 2 \mathrm{C}$, $\mathrm{C} 2 \mathrm{M}$ and $\mathrm{M} 3 \mathrm{C} 2$ are similar, but the performance of $\mathrm{C} 2 \mathrm{C}$, $\mathrm{C} 2 \mathrm{M}$, and $\mathrm{M} 3 \mathrm{C} 2$ is case-specific and dependant on the geometric characteristics of the point clouds. It is not necessary to apply all these three approaches if the performance of them in the case herein can be evaluated. To evaluate the performance of each approach, we need to compare the difference between calculated values and true values. However, in reality, the true value of displacement based on point clouds are not known. Thus, the point clouds are artificially rearranged so that the distance between a pair of point cloud is preknowledge.

In this research, the point clouds of interest are surface of SMW and ring beam. A typical section of ring beam was segmented from the original point cloud of Scan 1 as shown in Figure 9 (a). An image of that section is shown in Figure 9 (b). It can been seen the surface of the ring beam is neat concrete with minor abrasive damages. Then the point cloud is reoriented in the horizontal $x-y$ plane. Random half-resolution sub-sample was conducted on the point cloud shown in Figure 9 (a) for two times to produce two subsampled point clouds. So that these two subsampled point clouds are identical in terms of macroscopic geometric characteristic such as mean centre position, dimension, and roughness. But they are different in distribution of individual points. Their relationship is similar to that of two scans of a same object at same time. One of the subsampled point clouds is defined as the reference cloud. The other subsampled point cloud was duplicated into three identical point clouds and the three point cloud artificially translated from the original position in $\mathrm{z}$ direction by $0 \mathrm{~m}, 0.001 \mathrm{~m}$ and $0.01 \mathrm{~m}$ respectively. And the distance between the translated clouds and the reference cloud are calculated using $\mathrm{C} 2 \mathrm{C}, \mathrm{C} 2 \mathrm{M}$, and $\mathrm{M} 3 \mathrm{C} 2$ algorithms respectively. The calculation parameters for $\mathrm{M} 3 \mathrm{C} 2 \operatorname{are} \mathrm{D}_{\mathrm{c}}=$ $0.1 \mathrm{~m}, \mathrm{D}_{\mathrm{n}}=0.1$ and $\mathrm{d}=0.1 \mathrm{~m} . \mathrm{C} 2 \mathrm{C}$ method significantly overestimate distance between two point cloud when the true displacement is 0 and $0.001 \mathrm{~m}$. The $\mathrm{C} 2 \mathrm{M}$ method and $\mathrm{M} 3 \mathrm{C} 2$ method performed well for all three cases. 
Figure 9 (a) indicates point clouds of a typical section of ring beam surface (b) indicates image of the typical section of ring beam surface
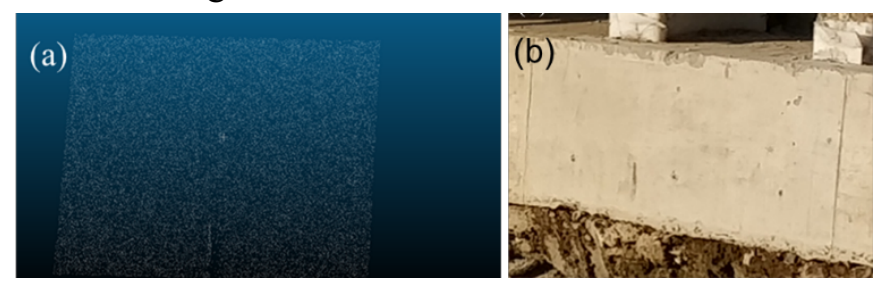

A typical section of SMW point was segmented as shown in Figure 10 (a) and it image is shown in Figure 10 (b). It can been seen that the surface of SMW is a mixture of cement and soil and quite rippled. It is expected the calculation of the displacement of SMW would be more erroneous. Following the same steps described the previous paragraph, the calculated displacements of each approach are compared to true displacement. Again C2C method significantly overestimate distance between two point cloud when the true displacement is 0 and $0.001 \mathrm{~m} . \mathrm{C} 2 \mathrm{M}$ is more accurate than $\mathrm{M} 3 \mathrm{C} 2$ when the true displacement is $0.001 \mathrm{~m}$. $\mathrm{M} 3 \mathrm{C} 2$ is more accurate than $\mathrm{C} 2 \mathrm{M}$ when the true displacement is $0.01 \mathrm{~m}$. But it should be noted that all 3 approaches underestimate the displacement when the true displacement is $0.01 \mathrm{~m}$.

To summarise, the accuracy of $\mathrm{C} 2 \mathrm{M}$ and $\mathrm{M} 3 \mathrm{C} 2$ are similar and these two methods are both capable of producing the direction of displacement. For the convenience of analysis, only C2M method was used to calculate the displacement of structures because the results $\mathrm{M} 3 \mathrm{C} 2$ are potentially dependent on its calculation parameters.

Figure 10 (a) indicates point clouds of a typical section of SMW surface (b) indicates image of the typical section of SMW surface

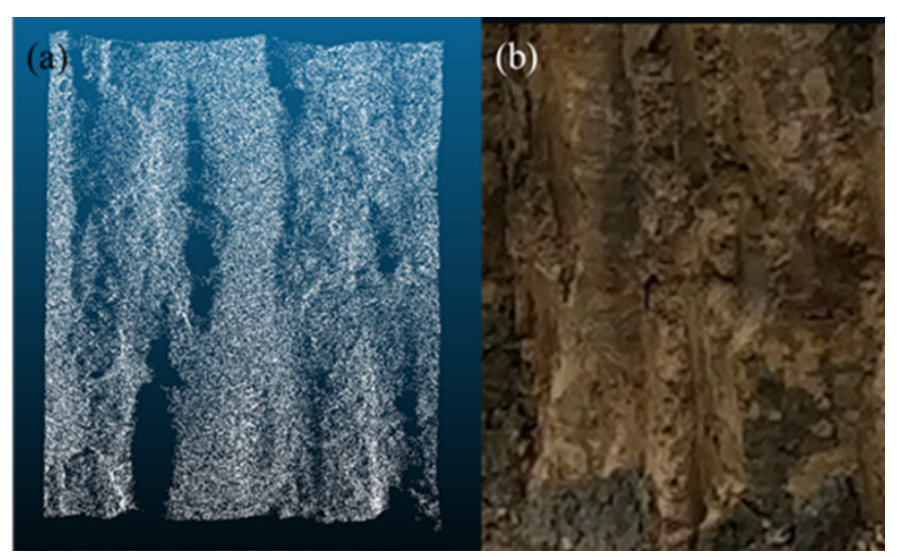

\section{Results of displacement calculation}

For all the displacement results, negative means displacement towards the excavation and positive means displacement away from excavation.
Firstly, the displacement at the centre of the monitored ring beam section is calculated. As it is just one piece, the PAM method is not applicable. Thus, only C2M approach is used. Point clouds at the centre of ring beam were segmented as shown in Figure 11. The point cloud of $1^{\text {st }}$ Scan was used as reference cloud and its displacement is set to be 0 . All the point cloud of sequential scans were compared to the reference cloud to calculate the displacement. The calculated displacement at the centre of the beam via point cloud are plotted together with measured displacement by contractor using total station in Figure 12. The horizontal axis represents the relative time and vertical axis displacement. The date of first scan was regarded as 0 day and the negative displacement is in the direction towards the excavation. It is expected that the displacement measured via point cloud displayed some random uncertainty due to alignment and calculation errors but the global trends are generally matched with the total station measurement.

Figure 11 Segmentation and calculation of displacement at the centre of ring beam

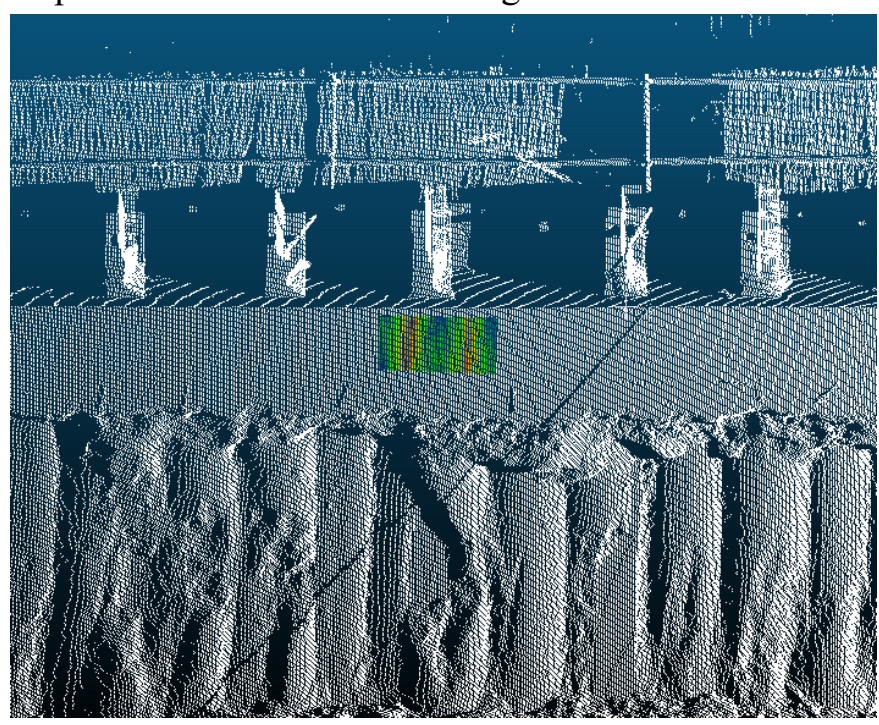

Figure 12 Displacement at the centre of beam

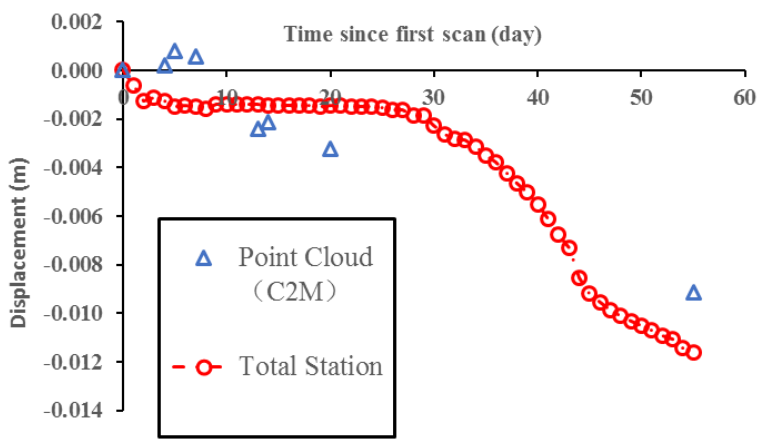

The displacement profile of the ring beam across its length is also calculated using C2M and PAM. As Shown in Figure 13, the entire ring beam surface across its length is segmented into 12 sections. 1 length of $1^{\text {st }}$ section on the left hand side is 1.3meter long and the others are 2.6-metre long. The displacement 
profile on $19^{\text {th }}$ July and $23^{\text {rd }}$ August relative to the first scan $\left(29^{\text {th }}\right.$ June) are shown in Figure 14. The horizontal axis represents the length of the beam and the vertical axis displacement. The results produced using $\mathrm{C} 2 \mathrm{M}$ and PAM are similar to each other for both dates, which means the calculation is appropriate. It is obvious that the ring beam was moving towards the excavation across its length. The displacement at the centre of the ring beam was most significant comparing to the rest of the sections. This behaviour is reasonable because both ends of the ring beam was supported transversely.

Figure 13 calculation of displacement profile across its length

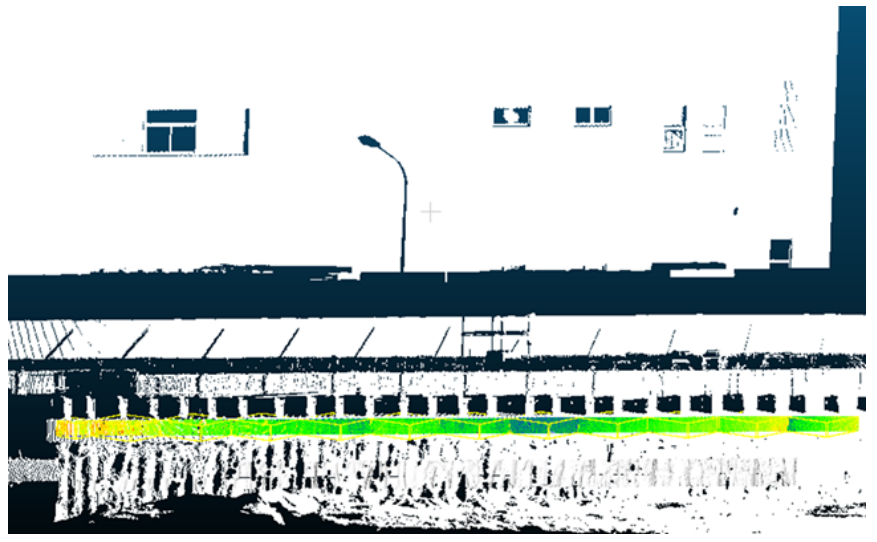

Figure 14 Displacement profile across its length

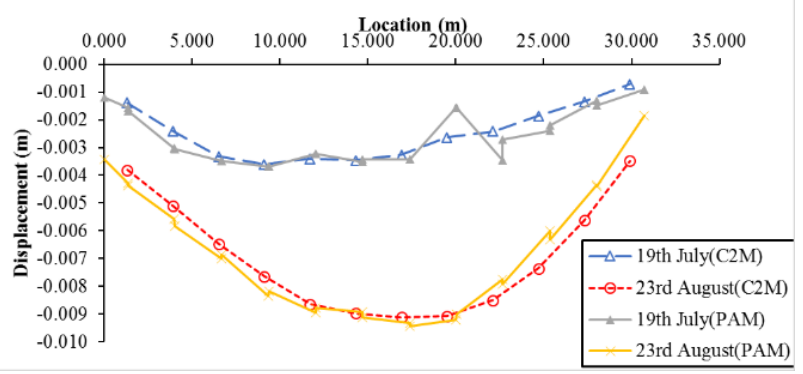

A section at the centre of the ring beam and SMW is segmented vertically along its depth (Figure 15) and the displacement profile across the depth are calculated using C2M and PAM (Figure 16). The displacement profile of the soil behind the SMW are also plotted in Figure 16. The vertical axis represents the depth from the top of inclinometer tube and horizontal axis displacement. The ground surface level is at $0.5 \mathrm{~m}$. For the results on July 19rd, the calculated displacements using C2M and PAM have similar value and general trend but the PAM displacement presents much more erroneous variation at depth from 1.2 to $1.6 \mathrm{~m}$ and 2.8 to $3.2 \mathrm{~m}$. Because at those depth, the SMW surface displayed strong local curvature and tilting which impairs the feasibility of PAM. From 1.2 to $1.6 \mathrm{~m}$, it is the around the connection of SMW and ring beam and the surface where soil remains on the SMW wall surface. From 2.8 to $3.2 \mathrm{~m}$, it was close to the excavation depth and soil were deposited at the corner formed by SMW and ground surface. For the displacement on $23^{\text {rd }}$ August, similar discrepancy is observed and also generally the PAM displacement is larger than that of $\mathrm{C} 2 \mathrm{M}$ by $3 \mathrm{~mm}$. For both the PAM and $\mathrm{C} 2 \mathrm{M}$ displacement, displacement is almost uniform across the depth, which means, the ring beam and SMW were moving horizontally as a rigid body towards the excavation but bending or tilting was not observed. It is curious that displacement of the neighbouring soil measured by inclinometer is not consistent the SMW. Displacement of the soil is much larger than SMW. It increases with depth and reaches maximum at approximately 2 metres above the maximum excavation depth $(5.5 \mathrm{~m})$. In the Chinese design code for excavation(China, 2009), the displacement profile measurement over depth for the SMW and that for neighbouring soil are assumed as equivalent. In the case herein, the assumption is likely to be untrue and it is suggested that further investigation should be done to verify this assumption.

Figure 15 segmentation of SMW

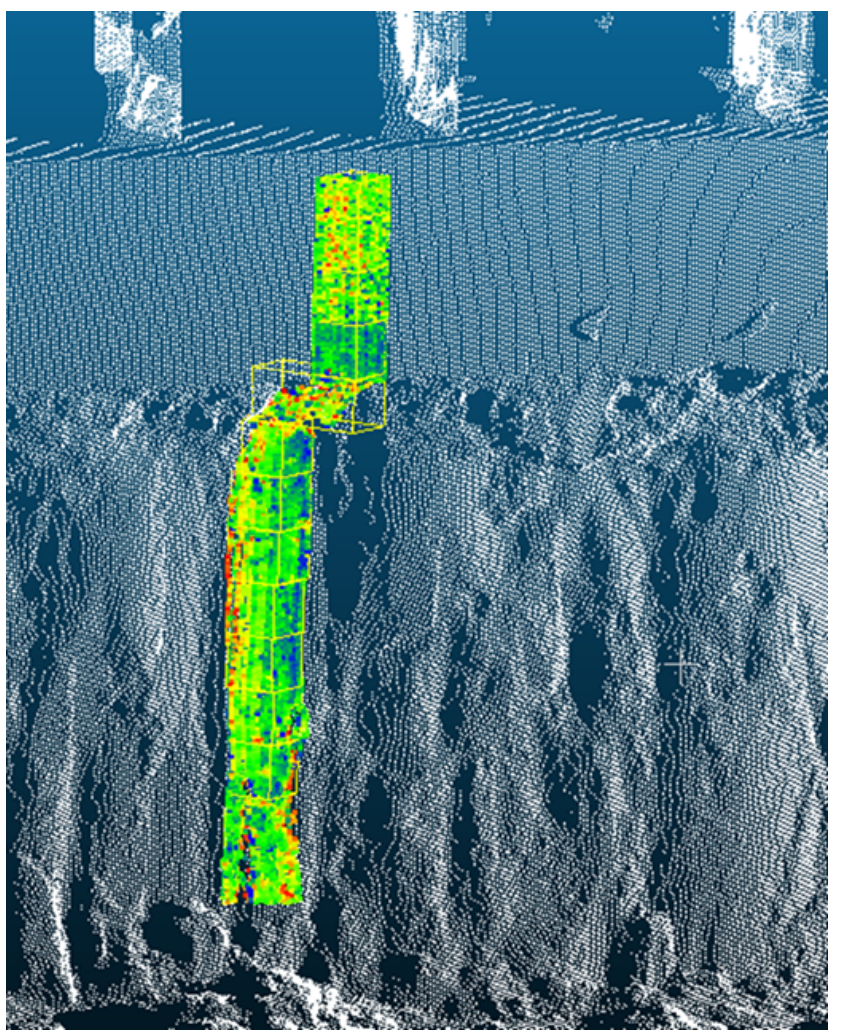


Figure 16 Displacement profile of SMW along its depth

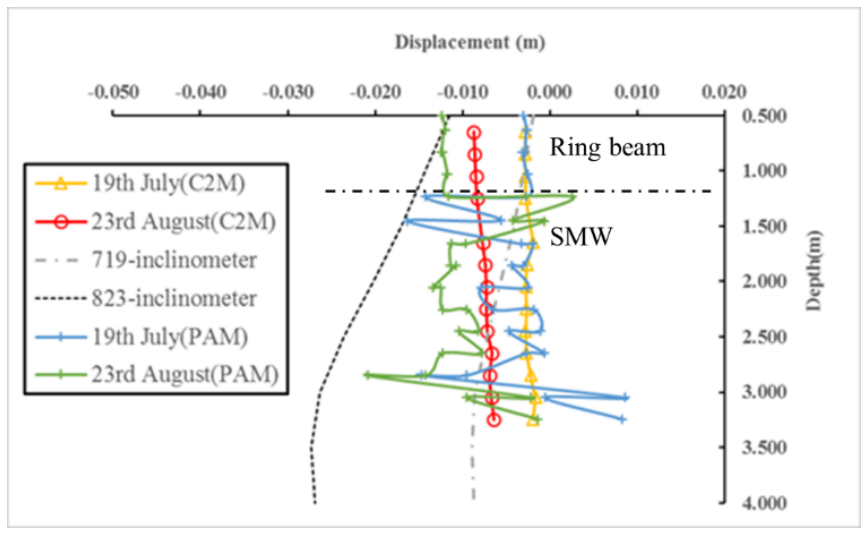

\section{Conclusion}

In this research, terrestrial laser scanning and 3D point cloud analysis were conducted on an open excavation site for the purpose of structural monitoring. The conclusions are summarised as follows:

- Comparing to traditional measurement techniques in structure monitoring, the terrestrial laser scanning and $3 \mathrm{D}$ point cloud analysis offer higher spatial resolution but lower accuracy.

- The accuracy of the calculated displacement via 3D point cloud is not sufficient for monitoring of daily increment change but may be applied for monitoring of cumulative change.

- Currently, the laser scanning measurement cannot replace traditional techniques but can serve as a supplementary to capture the general behaviour of the entire structure.

- Chinese design code for excavation(China, 2009), assumes the displacement profile measurement over depth for the SMW and that for neighbouring soil are equivalent, which is not true in the case studied herein. This assumption in design code may be revised based on further investigation.

\section{Acknowledgements}

The authors are grateful to Suzhou Zhonagyan Survey Company and Nantong Forth Construction Company for their assistance onsite.

\section{References}

ABELLÁN, A., JABOYEDOFF, M., OPPIKOFER, T. \& VILAPLANA, J. M. 2009. Detection of millimetric deformation using a terrestrial laser scanner: experiment and application to a rockfall event. Nat. Hazards Earth Syst. Sci., 9, 365-372.

ACIKGOZ, S., SOGA, K. \& WOODHAMS, J. 2017. Evaluation of the response of a vaulted masonry structure to differential settlements using point cloud data and limit analyses. Construction and Building Materials, 150, 916-931.
BREMER, M. \& SASS, O. 2012. Combining airborne and terrestrial laser scanning for quantifying erosion and deposition by a debris flow event. Geomorphology, 138, 4960 .

CHINA, M. O. H. A. U.-R. D. O. T. P. S. R. O. 2009. Technical Code For Monitoring Of Building Foundation Pit Engineering : GB 50497-2009.

CRESPO-PEREMARCH, P., TOMPALSKI, P., COOPS, N. C. \& RUIZ, L. Á. 2018. Characterizing understory vegetation in Mediterranean forests using full-waveform airborne laser scanning data. Remote Sensing of Environment, 217, 400-413. GEOSYSTEMS, L. 2015. Cyclone.

GEOSYSTEMS, L. 2017. Leica ScanStation P30/P40

Product specifications. Heerbrugg, Switzerland.

LAGUE, D., BRODU, N. \& LEROUX, J. 2013. Accurate 3D comparison of complex topography with terrestrial laser scanner: Application to the Rangitikei canyon (N-Z). ISPRS Journal of Photogrammetry and Remote Sensing, 82, 10-26.

MILAN, D. J., HERITAGE, G. L. \& HETHERINGTON, D. 2007. Application of a 3D laser scanner in the assessment of erosion and deposition volumes and channel change in a proglacial river. Earth Surface Processes and Landforms, 32, 1657-1674.

MOHAMAD, H., SOGA, K., BENNETT, P. J., MAIR, R. J. \& LIM, C. S. 2012. Monitoring Twin Tunnel Interaction Using Distributed Optical Fiber Strain Measurements. Journal of Geotechnical and Geoenvironmental Engineering, 138, 957967.

NGUYEN, H., FERNANDEZ-STEEGER, T., WIATR, T., RODRIGUES, D. \& AZZAM, R. 2011. Use of terrestrial laser scanning for engineering geological applications on volcanic rock slopes - An example from Madeira island (Portugal).

O'NEAL, M. A. \& PIZZUTO, J. E. 2011. The rates and spatial patterns of annual riverbank erosion revealed through terrestrial laser-scanner surveys of the South River, Virginia. Earth Surface Processes and Landforms, 36, 695-701.

OLSEN, M., JOHNSTONE, E., DRISCOLL, N., ASHFORD, S. \& KUESTER, F. 2009. Terrestrial Laser Scanning of Extended Cliff Sections in Dynamic Environments: Parameter Analysis.

PESCI, A., CASULA, G. \& BOSCHI, E. 2011. Laser scanning the Garisenda and Asinelli towers in Bologna (Italy): Detailed deformation patterns of two ancient leaning buildings. Journal of Cultural Heritage, 12, 117-127.

PETLEY, D. N., LIM, M., ROSSER, N. J., ALLISON, R. J. \& DUNNING, S. A. 2005. Terrestrial laser scanning for monitoring the process of hard rock coastal cliff erosion. Quarterly Journal of Engineering Geology and Hydrogeology, 38, 363-375.

RIVEIRO, B., DEJONG, M. J. \& CONDE, B. 2016. Automated processing of large point clouds for structural health monitoring of masonry arch bridges. Automation in Construction, 72, 258-268.

SCHÜRCH, P., DENSMORE, A. L., ROSSER, N. J., LIM, M. \& MCARDELL, B. W. 2011. Detection of surface change in 
complex topography using terrestrial laser scanning: application to the Illgraben debris-flow channel. Earth Surface Processes and Landforms, 36, 1847-1859.

SOFTWARE, G. 2018. CloudCompare

SUCHOCKI, C. \& KATZER, J. 2018. Terrestrial laser scanning harnessed for moisture detection in building materials - Problems and limitations. Automation in Construction, 94, 127-134.
VOROBYEV, A., GARNIER, F., VAN DIJK, N. P., HAGMAN, O. \& GAMSTEDT, E. K. 2018. Evaluation of displacements by means of 3D laser scanning in a mechanically loaded replica of a hull section of the Vasa ship. Digital Applications in Archaeology and Cultural Heritage, 11, e00085.

XU, X., YANG, H. \& NEUMANN, I. 2018. Deformation monitoring of typical composite structures based on terrestrial laser scanning technology. Composite Structures, 202, 77-81. 